
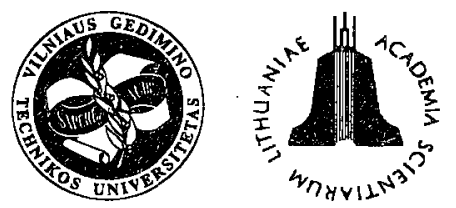

ISSN 1648-4142 TRANSPORT

http:/www.vtu.lt/english/editions

TRANSPORT - 2002, Vol XVII, No 3, 85-90

\title{
RESEARCH OF BRAKING PECULIARITIES OF USED CARS
}

\author{
Valentinas Mitunevičius ${ }^{1}$, Saulius Nagurnas ${ }^{2}$ \\ ${ }^{1}$ Joint - Stock Co. "Transporto studijos", Lentvario g. 7, LT-2028 Vilnius, Lithuania. E-mail: V.Mitunev@takas.lt \\ ${ }^{2}$ Department of Automobile Transport, Vilnius Gedininas Technical University, J. Basanavičiaus g. 28, \\ LT-2009Vilnius, Lithuania.E-mail: saunag@itivtu.lt
}

Received 200202 26; accepted 20020418

\begin{abstract}
This paper briefly describes some analysis of a car braking process - the peculiarities of car wheel-to-road adhesion, the influence of distribution of braking forces on car stability between front and rear axles.

The requirements of EU Directive 71/320/EEC to braking force coefficients of car front and rear axles are exposed. Structural designs of braking systems are analyzed with respect to their meeting the EU standards.

Experimental measurements of braking force coefficients for some models of cars which are used in Lithuania, are presented with the analysis how these coefficients meet the EU standards.

The analysis of test results, suggestions for the ratio of braking forces of car front and rear axles are presented.
\end{abstract}

Keywords: braking, longitudinal force coefficient, front wheels braking, rear wheels braking, car stability, requirements of braking, braking system, braking efficiency.

\section{Introduction}

The most effective braking can be reached in the case when the longitudinal force coefficient (braking force coefficient (see section 2) of the car front wheel axle equals the coefficient of the rear wheel axle.

The practical distribution of braking forces depends on different factors, such as brake control, structure and status of mecharisms, wheel loading, car speed a. o. During the intensive braking higher reliability of wheel locking at first exists for the rear axle, because the braking force coefficient of the rear wheels usually can sooner reach and exceed the value of the wheel-to-road adhesion coefficient in comparison with the braking force coefficient of the front wheels [1]. This factor is negative from the point of view of traffic safety - the car becomes unstable. The contrary situation when the locking of front wheels takes place sooner is less dangerous: the car can become uncontrolled, but it remains stable (see more in section 2).

Taking into account the described problems the car must be designed and made so that locking of rear wheels would not occur earlier than that of front wheels during the emergency braking. This demand is formulated in the legal documents of the European Union $[2,3]$. The requirements of the 71/320/EEC Directive for the braking force coefficients of $M_{I}$-class cars are presented in the third section.

For the realization of the proper diagram of the distribution of braking forces (see section 4) various regula- tors of braking forces (mechanical, electronical) and antilock braking systems of various structures are used [4-7]. Theoretical foundations of braking system design are briefly described in the fourth section.

Fairly aged cars are being used in Lithuania now (average age is about 16 years). Many of them are not only obsolete morally, but their technical resource is out of limits also. So most of them do not meet the technical requirements prescribed. For these reasons the authors made efforts to study how the parameters of such used cars meet the 71/320/EEC Directive for ratio of braking forces of front and rear axles. The method and the results of the carried out tests are presented in the fifth section.

The analysis of the test results and proposals for the improvement of car brake control are presented in the conclusions of this paper.

\section{The Process of Car Braking}

2.1. The longitudinal force coefficient during braking. Deceleration coefficient

The ratio of longitudinal and perpendicular road reactions to a wheel is called the longitudinal force coefficient [8]:

$$
\mu_{x}=\frac{F_{x}}{F_{z}} .
$$

Any longitudinal force when it is being transmitted with the help of a wheel is restricted by the friction be- 
tween wheel and road.

The ratio of maximal longitudinal and perpendicular loading forces is called the maximum longitudinal force coefficient $\mu_{\text {.max }}$ :

$$
\mu_{x \max }=\frac{F_{x \max }}{F_{z}} .
$$

Potential properties of a wheel in accordance with the adhesion with the road can be characterized by the longitudinal adhesion utilization coefficient, which equals the ratio of the longitudinal force coefficient and the maximum longitudinal force coefficient:

$$
\varepsilon_{x}=\frac{\mu_{x}}{\mu_{x \max }} .
$$

This coefficient does not exceed 1,0 (for ideal braking $\varepsilon_{x}=1,0$ ).

The longitudinal force coefficient for every axle of a car which is being braked can be expressed as follows:

$$
\begin{gathered}
\mu_{x f}=\frac{B_{f}}{F_{z f}}, \\
\mu_{\lambda r}=\frac{B_{r}}{F_{z r}},
\end{gathered}
$$

here $B_{f}$-braking force of front axle; $B_{r}$-braking force of rear axle; $F_{\text {zf }}$ - perpendicular road reaction to wheels of front axle; $F_{z r}$-perpendicular road reaction to wheels of rear axle.

Perpendicular dynamic road reactions to car axles are defined by the following equations:

$$
\begin{aligned}
& F_{z f}=F_{z f s t a t}+m g \frac{h}{l} z=m g\left(\frac{l_{r}}{l}+\frac{h}{l} z\right) \\
& F_{z r}=F_{z r s t a t}-m g \frac{h}{l} z=m g\left(\frac{l_{f}}{l}-\frac{h}{l} z\right)
\end{aligned}
$$

here $F_{z \text { zftut }}, F_{z r s t a t}-$ static reactions to front and rear axles; $m$-mass of the car; $g=9,81 \mathrm{~m} / \mathrm{s}^{2}$ - free fall acceleration; $l_{r}$, $l_{f}$ - distances between car mass center and corresponding axles; $l$-wheelbase; $h$-height of mass center over the road surface; $\mathrm{z}$ - deceleration coefficient.

The deceleration coefficient can be calculated as follows:

$$
z=\frac{a_{x}}{g}
$$

here $a_{x}-$ car deceleration $\mathrm{m} / \mathrm{s}^{2}$.

The deceleration coefficient can be expressed using the braking forces:

$$
z=\frac{B_{f}+B_{r}}{m g} .
$$

\subsection{Car stability during braking}

There are two kinds of stability: 1) trajectory and 2) course. The first one characterizes the car ability of copying a presettled curvilinear trajectory of motion and the second characterizes the ability to retain the straight-line motion.

Let us examine the cases which can occur during braking [1]:

1. The loss of trajectory stability as the result of front wheels locking. In such situation wheels lose the ability of side force transfer and the car remains uncontrolled. It moves in the straight direction only irrespective of the position of steering wheels. Therefore a sidelong slide of the front axle can take place at speed $V_{s l}$ (see Fig 1, b). Then the front axle begins the motion around the turning center $O$ at velocity $V=\sqrt{V_{a}^{2}+V_{s l}^{2}}$. The component $F_{j}$ of the centrifugal force $F_{i s}$ reduces the sidelong slide of the front axle, therefore the car stability is regained as the braking interrupts.

2. The loss of course stability occurs when the rear wheels become locked. In such a case the force $F_{y}$ does not suppress the rear axle slide, but intensifies it (see Fig 1, a). Therefore the destabilizing torque arises $M_{d}=F_{y} l_{f}$, and the slide develops.

It is known [1] that if the wheels of the rear axle lock and the car deviates about $20^{\circ}$, it becomes unstable and even after the interruption of braking the car response not adequate to control actions is observed.

The perpendicular dynamic road reaction to wheels $F_{z}$ (see equations (5)) depends on car mass, location of its mass center, structure of suspension, character of car motion. During braking a higher loading acts the front axle, but the corresponding dynamic weight is "taken off" the wheels of the rear axle. There is a probability of locking the wheels of the rear axle at first because of consider-

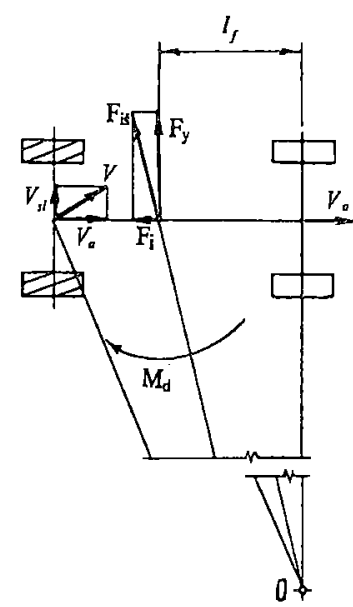

a)

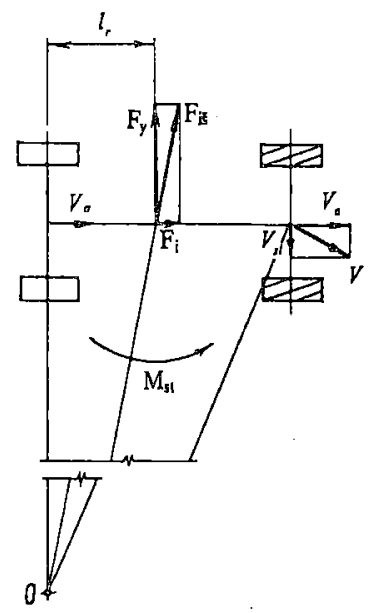

b)
Fig 1. Critical cases of car braking: a) locked rear wheels; b) locked front wheels 
able decrease of the road-to-wheel reaction $F$, which can be expressed as follows:

$$
F_{\Sigma}=\sqrt{F_{x}^{2}+F_{y}^{2}} \leq \mu_{\max } \cdot F_{z},
$$

here $F_{y}$ - cross directed road-to-wheel reaction.

As it seen from the last equation, greater $F_{x}$, (i.e. more intensive braking) provokes the decrease of the car stability.

\section{Requirements of Braking Efficiency for Cars of $M_{1}$ - class}

3.1. The deceleration coefficient $z$ (for the case $\left.\mu_{x}=0,2 \ldots 0,8\right)$ would be as follows [2]:

$$
z \geq 0,1+0,85\left(\mu_{x \max }-0,2\right) \text {. }
$$

Then the longitudinal adhesion utilization coefficient must meet the following requirement:

$$
\varepsilon_{x}=\frac{z}{\mu_{x \max }}>0,85-\frac{0,07}{\mu_{x \max }}
$$

3.2. For any car loading the adhesion straight line of the front axle $\mu_{x f}$ must be situated higher than the corresponding line of the rear axle $\mu_{x r}$ (see Fig 2).

For cars of $\mathrm{M}_{1}$-class, when the adhesion coefficient $\mu_{x}$ is in the limits $0,15 \ldots 0,8$, the longitudinal force coefficient of front wheels must be equal to or higher as compared with such coefficient of rear wheels. But for such cars $\mu_{x r}>\mu_{x f}$ is allowed when $z=0,3 \ldots 0,45$. In such a case the longitudinal force coefficient must meet the condition $\mu_{x r} \leq z+0,05$ (see Fig 2).

\section{Structural Special Features of the Braking System that Enable Meeting of the Established Requirements}

If the car has no regulator of braking forces, the ratio of braking forces of the front and rear axles is constant.

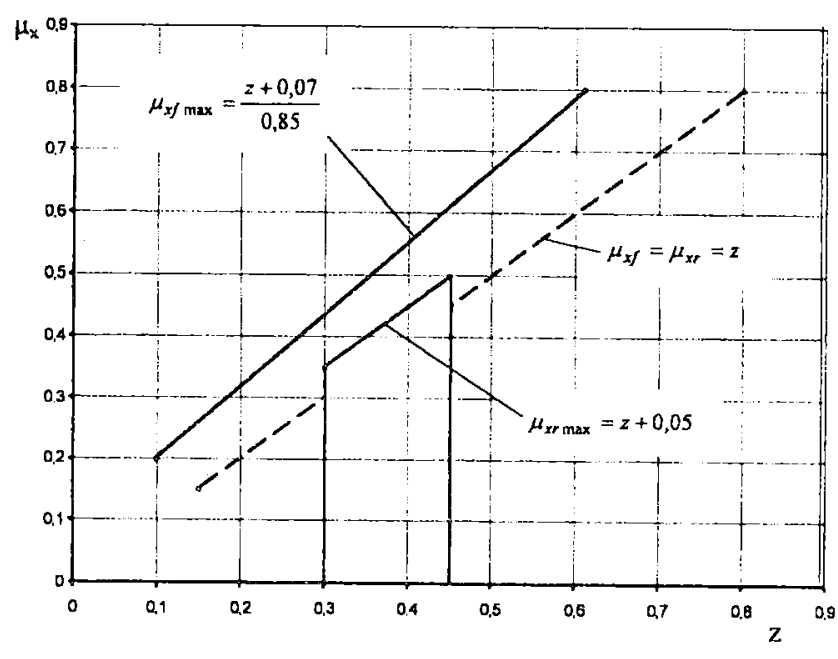

Fig 2. Requirements for $M_{1}$-class car braking
The diameter of pistons of braking mechanisms of the front wheels is larger than of the rear ones, thus a direct proportion between braking forces of front and rear axles exists $B_{f}=$ const. For such structure of the braking sys tem graphs of the longitudinal force coefficients of the front and rear axles have the form shown in Fig 3 [9].

Up to the point $z=0,8 \mu_{x f}>\mu_{x r}$. If $z=1,0$, then the probability of locking is greater for the rear wheels. If longitudinal force coefficients for both axles are the same and are equal to $z_{r i b}\left(z_{r i b}=\mu_{\text {mmax }}\right)$, i.e. $\mu_{x f}=\mu_{r r}=z_{r i b}$, then we have the ideal braking. Really the car braking system can be designed for ideal braking only for a dynamic situation, when $\mu_{x}=0,8 ; \mathrm{z}=0,8$; the car is fully loaded.

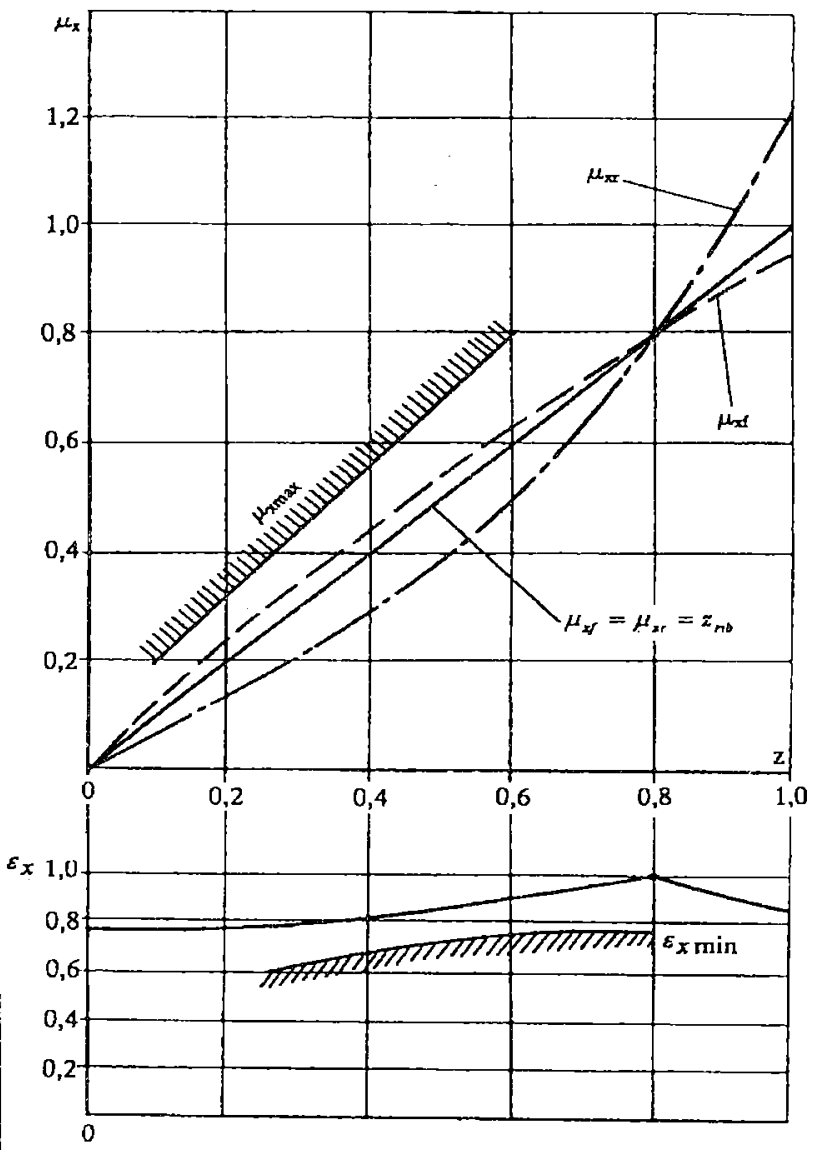

Fig 3. Diagrams of braking process in the case of a linear dependence between braking forces of front and rear axles

Then $\mu_{x f}=\mu_{x r}=z=0,8 ; \varepsilon_{x}=1,0$, i.e. wheel-to-road adhesion is used at $100 \%$ (see Fig 3 ) and both axles of the car are being braked equally.

If the wheels brake the car with the same efficiency, efforts are being made to draw nearer the graphs of coefficients $\mu_{x f}$ and $\mu_{x r}$ to the ideal one. For this reason the need of special means arises enabling a proper ratio of pressures in the braking systems of the front and rear 
wheels. Because of the increased danger of locking of rear wheels (if compared with the front ones) attempts are being made for retaining the lower pressure in the braking system of rear wheels, if pressure in the braking system of front wheels exceeds some limit during the emergency braking. Some kinds of braking force regulators are used for this purpose.

The use of such regulators modifies the form of diagrams of the braking process (see Fig 4) - in the diagram of $\mu_{x r}$ a brake is seen, which draws nearer this diagram and characteristic of $\varepsilon_{x}$ to the ideal one.

Efficiency of braking force regulators is very high for small wheelbase cars with a highly located mass center and in the case of great difference between static and dynamic perpendicular loading.

The operation of such regulators is influenced by the accuracy of installation, residual deformation of suspension (e.g. springs), turning of rear axle during braking a.o. Therefore it can be asserted that braking force regulators allow restricted improvement of car stability during braking.

More effective braking can be reached with the help of wheel anti-lock braking systems (ABS) which better

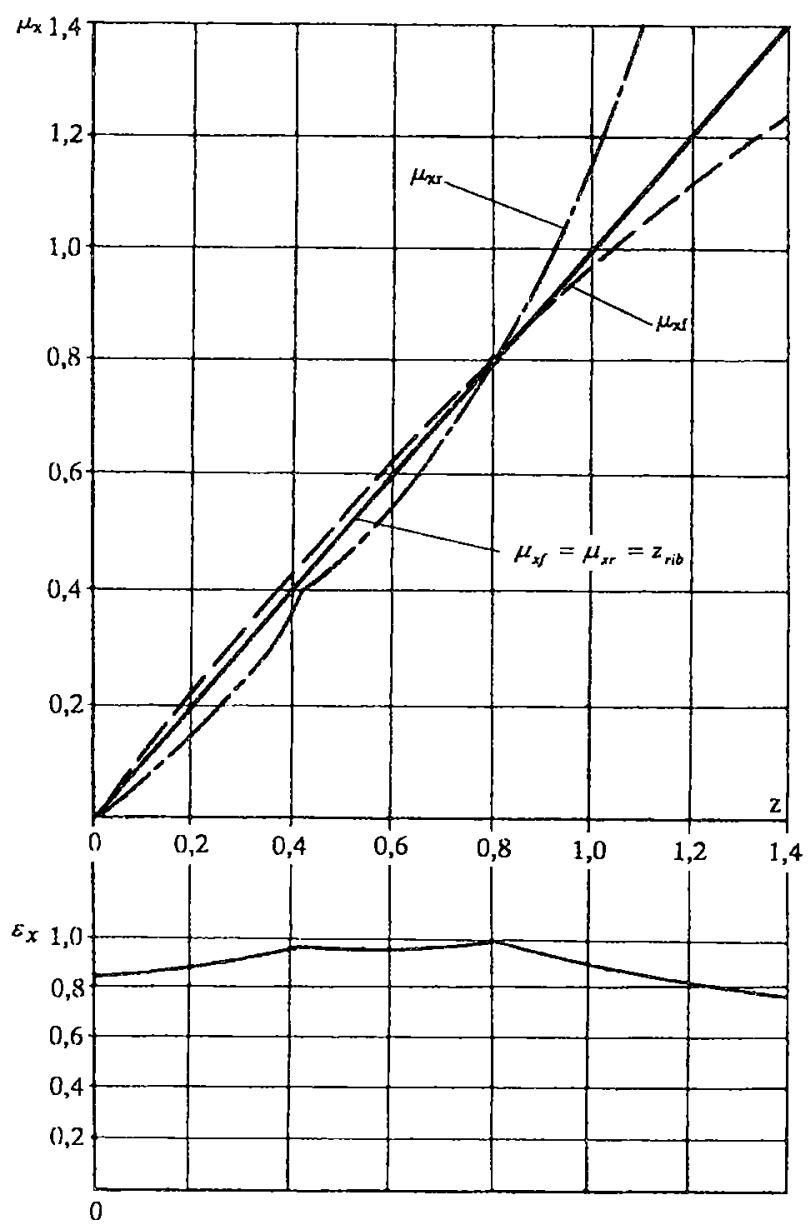

Fig 4. Diagrams of a braking process with braking force regulation accommodate themselves to alternating traffic conditions $[4,5,7]$.

The influence of ABS is not described in this paper because the studied cars had no ABS.

\section{Experiments of Car Braking Efficiency}

\subsection{Goals and methods of experiments}

With the goal of examination how the main car braking systems meet the 71/320/EEC Directive the longitudinal force coefficients $\mu_{x f}$ and $\mu_{x r}$ for front and rear axles were measured in 26 cars. The results showed which axle locked first during braking.

As braking by the main brakes goes on dynamically the dynamic experiment allows better discovering of imperfections characteristic to such braking, therefore the experiments were carried out on the plate-type test bench for brake testing HEKA UNIVERS A2.

The longitudinal force coefficients $\mu_{x f}$ and $\mu_{x r}$ for front and rear axles were calculated in accordance with formulae (4).

Expressions for the calculation of perpendicular dynamic road reactions to front and rear axles can be obtained from (5):

$$
\begin{aligned}
& F_{z f}=m_{f} \cdot g+a_{x} \cdot \frac{h}{l} \cdot m, \\
& F_{z r}=m_{r} \cdot g-a_{\lambda} \cdot \frac{h}{l} \cdot m,
\end{aligned}
$$

here $m_{f}$ and $m_{r}$ - masses of car front and rear axles, $\mathrm{kg} ; m$ - car mass, $\mathrm{kg} ; h /$ - ratio of height of car mass center and car wheelbase (during the experiments $h / l$ was accepted equal to 0,225 for all cars).

For the calculations of dynamic perpendicular loadings $F_{z f}$ and $F_{z r}$ in accordance with (11) knowing the braking deceleration $a_{x}$ is necessary. It was measured with the help of the portable measuring instrument VZM 100.

The obtained values of coefficients $\mu_{x /}$ and $\mu_{x r}$ were compared with each other and decisions were made about car stability during braking and about the meeting of braking forces the EU standards.

For more exhaustive examination of braking efficiency cars FORD ESCORT, HONDA CIVIC, LADA 2101 were braked 4 times by front axles and 3 times by rear ones. The obtained results were used for drawing $\mu_{x f}=f(z)$ and $\mu_{x r}=f(z)$ for these cars together with the braking efficiency limits $\mu_{x f \max }$ and $\mu_{x r \max }$ for front and rear axles established by the EU standards. These graphs are shown in Fig 5 - Fig 7 (see also Fig 2).

Other cars were braked one time by front and one time by rear axle each. Values of $z, \mu_{x f}$ and $\mu_{x r}$, obtained in the experiments are shown in Fig 8. The comparative dissipation of braking efficiency for front and rear axles is seen for these cars together with the straight line $\mu_{x}=z$ of ideal braking. 


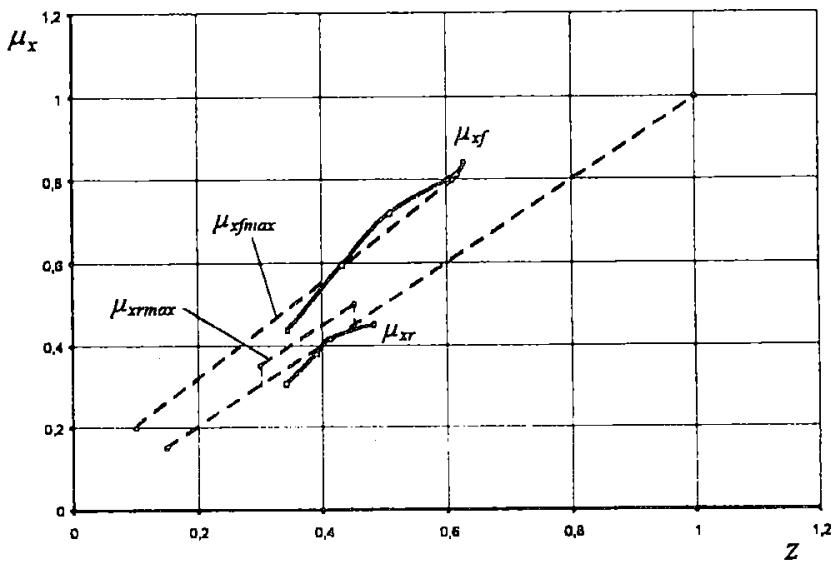

Fig 5. Braking diagrams of a FORD ESCORT car

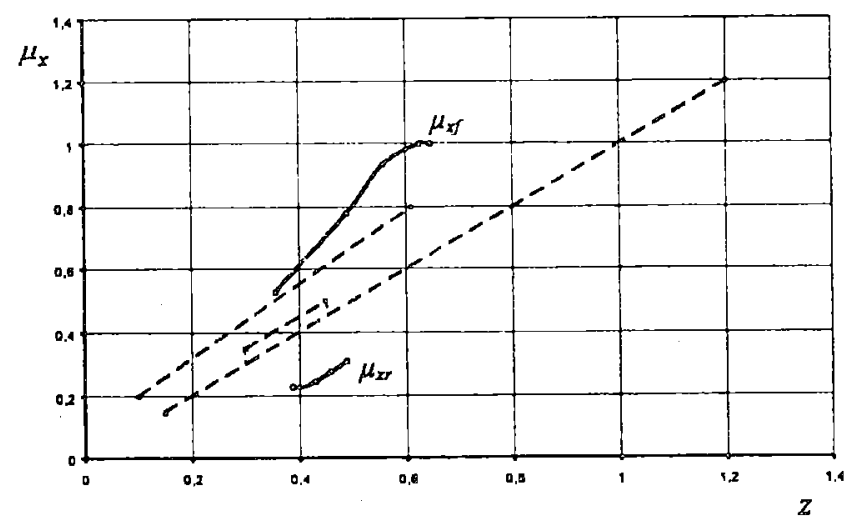

Fig 6. Braking diagrams of a HONDA CIVIC car

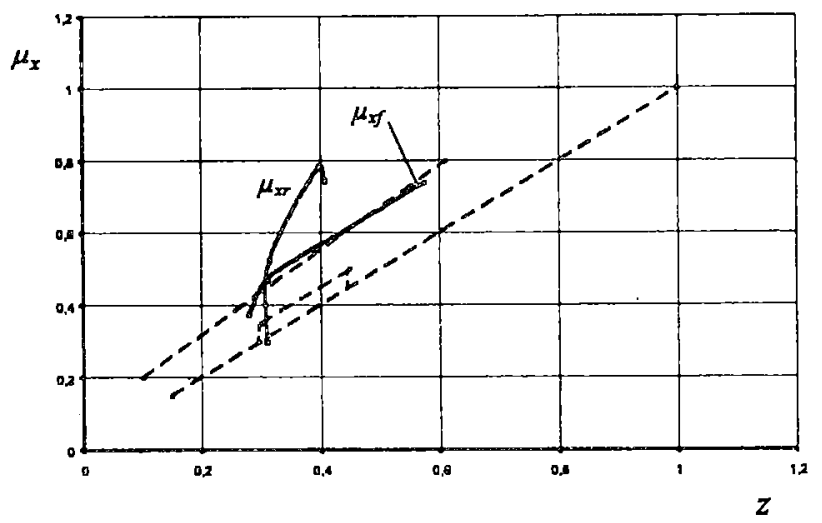

Fig 7. Braking diagrams of a LADA $2101 \mathrm{car}$

\section{Conclusions}

1. The obtained results showed that 8 cars from 26 did not meet the requirements of 71/320/EEC Directive: the braking efficiency of the rear axle (longitudinal force coefficient $\mu_{\lambda r}$ ) was larger than that of the front axle. Rear wheels of FORD SIERRA, OPEL OMEGA, two LADA 2101

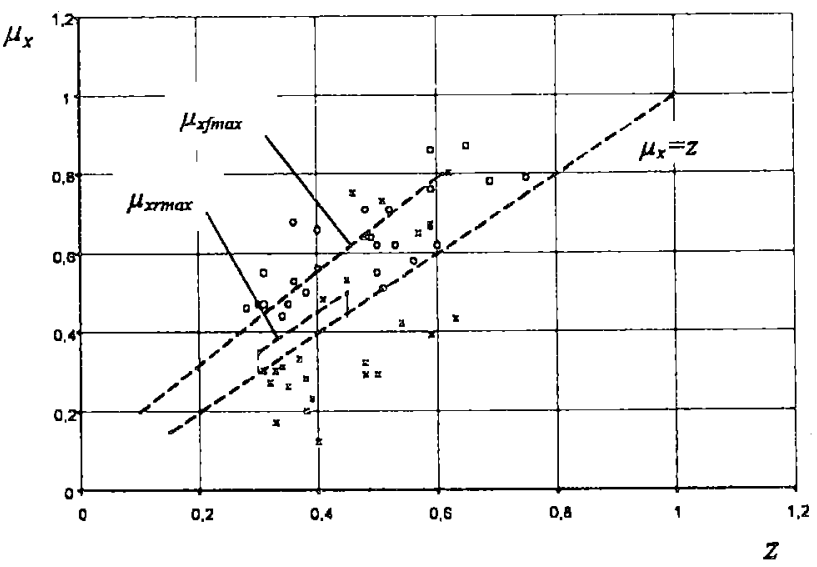

Fig 8. Distribution of longitudinal force coefficients for front (0) and rear $\left(^{*}\right)$ axles

and LADA 2106 cars braked too intensively: $\mu_{x r}$ was $1,1 \ldots 1,4$ times larger than $\mu_{x f}$. Therefore it can be predicted that approximately $30 \%$ of cars running in Lithuania do not meet at least one of the main requirements ensuring car stability during braking.

2. Longitudinal force coefficients $\mu_{x-r}$ for rear axle of cars FIAT TIPO, of three HONDA CIVIC, OPEL ASCONA, OPEL SENATOR, RENAULT 25 were even $2 . .4$ times less than such parameter for front axle. It means that during emergency braking front wheels can be locked first and the car can become uncontrolled. This situation as mentioned before is less dangerous from the point of view of traffic safety, if compared with the contrary one.

3. The analysis of average values of $\mu_{x f}$ and $\mu_{x r}$ established that the front wheels braked about 1,5 time more intensively than the rear ones.

4. As it is seen from the diagrams of FORD ESCORT, HONDA CIVIC and LADA 2101 cars, force coefficient $\mu_{x f}$ of all these cars meets the requirements with the exception of HONDA CIVIC. The graph of this car is far from $\mu_{x f \max }$ and still farther from the longitudinal force coefficient $\mu_{x r}$. It can result in too early locking of the front wheels during braking (see p. 2).

Distribution of coefficients $\mu_{x r}$ for cars FORD ESCORT and HONDA CIVIC meets the requirements of EU Directive 71/320/EEC. Graph $\mu_{x r}$ of the LADA 2101 car is situated higher than graph $\mu_{x f \max }$. It means that during intensive braking the rear axle will lock first and the car will remain unstable.

5. Checking the braking system state the evaluation of faults of braking force regulators is of great importance. There are also important cases when braking of rear wheels is too weak (it was so with cars FIAT TIPO and HONDA CIVIC). As any repair of braking regulator without taking it off, often is fairly problematic fixing of proper ratio of total braking forces $B_{f} B_{r}$ can be recommended. If such checking is carried out on the plate - type test bench, the ratio must be not more than 5 . 


\section{References}

1. Ilarionov V. A., Morin M. M., Sergeyev N. M. Theory and design of automobiles (Теория и конструкция автомобиля). Moscow: Mashinostroyeniye, 1985. 368 p (in Russian).

2. Council Directive 71/320/EEC on the approximation of the laws of the Member States relating to the braking devices of certain categories of motor vehicles and their trailers. Brussel, 1998.

3. Regulation No 13. Uniform provisions concerning the approval of vehicles of categories $M, N, O$ with regard to braking. Geneva, 1995.

4. Austin L., Morey D. Recent advances in antilock braking systems and traction control systems. In: Proceedings of the Institution of Mechanical Engineers. Part D, Journal of Automobile Engineering, Vol 214, 2000, p 625-638.
5. Camey D. Continental Teves' electrohydraulic brake system. In: Automotive Engineering International, Vol 109, No 9,2001, p 50.

6. Electronic braking control developments. In: Automotive Engineering Intemational, Vol 107, No 2, 1999, p 125-127.

7. Electronic starts to handle stops. In: Automotive Engineer, Vol 26, No 1, 2001, p 18-19.

8. Mitunevičius V. Foundations of automobile dynamics: concepts, determinations and first principles of application. Textbook (Automobilių dinamikos pagrindai: sąvokos, apibrèžimai ir bendrieji taikymo principai. Mokomoji knyga). Vilnius: Technika, $1999.76 \mathrm{p}$ (in Lithuania).

9. Mitschke M. Dynamics of motorvechicles (Dynamik der Kraftfahrzeuge). Band A.: Drive and Braking (Antrieb und Bremsung). Springer-Verlag, 1982.182 p (in German). 